\title{
Molecular Investigation of MERS-CoV in Camels Related to Confirmed Human Cases in Saudi Arabia (2017-2019)
}

\section{Samy Kasem ${ }^{1,2}$, Ali Al-Doweriej ${ }^{1}$, Ibrahim Qasim ${ }^{1}$, Ali Nasser Alhufuf ${ }^{1}$, Nader Alharbi ${ }^{1}$, Sanad Alharbi ${ }^{1}$, Ahmed Youssef ${ }^{1,3 *}$}

${ }^{1}$ Ministry of Environment, Water and Agriculture, 65 King Abdulaziz Road, Riyadh, 11195, Kingdom Saudi Arabia; ${ }^{2}$ Department of Virology, Faculty of Veterinary Medicine, Kafrelsheikh University, Kafrelsheikh, El-Geish Street, 33516, Egypt; ${ }^{3}$ Department of Animal Hygiene and Zoonoses, Faculty of Veterinary Medicine, Suez Canal University, Ismailia, Egypt.

\begin{abstract}
The Middle East respiratory syndrome (MERS) caused by Coronavirus (MERS-CoV) is an emerged zoonotic infectious disease of increasing public health significance. Dromedary camels are the main MERS-CoV reservoirs and maintenance hosts, but the transmission mechanism to humans is still unknown. This study aimed to investigate the prevalence of MERS-CoV among camel herds that were probable sources of zoonotic infection to human cases in the Kingdom of Saudi Arabia (KSA), through three years (2017-2019). Molecular examination of nasal swabs collected from 449 camels was performed for the detection of the MERS-CoV genome using quantitative real-time PCR (qRT-PCR). The analysis of the questionnaire revealed that out of 91 human cases of MERS, 51 (56\%) of which were related to dromedaries and the rest had no relation to animals with a history of contact with camels or drinking raw milk or undercooked meat from camels. The percentage of human cases with suspected animal-acquired infections reached 100\% in Bahaa, Gazan, Makkah, Jouf, and Tabuk regions. The MERS-CoV genome was detected in 74 dromedaries (16.5\%) out of 449 camels examined by qRT-PCR. The positive cases of camels were distributed in eleven districts of Saudi Arabia. In conclusion, the detection of MERS-CoV genome among camel samples associated with confirmed MERS subjects suggested that the virus is prevalent in Saudi Arabia. This data supported the theory of zoonotic infections of MERS-CoV from camels.
\end{abstract}

Keywords | MERS-CoV, Dromedary camels, Zoonoses, Saudi Arabia

Received | April 26, 2021; Accepted | July 17, 2021; Published | September 25, 2021

*Correspondence | Ahmed I. Youssef, Ministry of Environment, Water and Agriculture, 65 King Abdulaziz Road, Riyadh, 11195, Kingdom Saudi Arabia, Email: ahmed_ibrahim@vet.suez.edu.edu

Citation | Kasem S, Al-Doweriej A, Qasim I, Alhufuf AN, Alharbi N, Alharbi S, Youssef A (2021). Molecular investigation of MERS-CoV in camels related to confirmed human cases in Saudi Arabia (2017-2019). Adv. Anim. Vet. Sci. 9(11): 1776-1780.

DOI | http://dx.doi.org/10.17582/journal.aavs/2021/9.11.1776.1780

ISSN (Online) | 2307-8316; ISSN (Print) | 2309-3331

Copyright $(\subseteq 2021$ Kasem et al. This is an open access article distributed under the Creative Commons Attribution License, which permits unrestricted use, distribution, and reproduction in any medium, provided the original work is properly cited.

\section{INTRODUCTION}

$\mathrm{T}$ The Middle East respiratory syndrome coronavirus (MERS-CoV) is an emerged disease in Saudi Arabia and Middle East countries causing serious respiratory infection in humans. Between September 2012 and the end of January 2020, the World Health Organization (WHO) was notified of 2519 MERS-CoV human cases, and 866 deaths recorded in 27 countries worldwide with the highest record in Saudi Arabia (WHO, 2020). Saudi
Arabia had the highest incidence and mortality rate in humans (2102 cases, 780 associated fatalities, and a $37.1 \%$ case-fatality rate) (WHO, 2019). Besides the significantly high mortality and morbidity rates, MERS-CoV infection provokes a risk for outbreaks in healthcare facilities (Cauchemez et al., 2013).

MERS-CoV is identified as a zoonotic disease by transmission from infected Dromedaries to contacted humans in endemic areas. However, little, non-sustained 
inter-human transmission has been observed, notably in clinical settings in Saudi Arabia (Conzade et al., 2018). There is a possibility of traveling infected human cases outside of the Middle East to the other countries that can spread the disease elsewhere. Moreover, the internal movement of camels inside the endemic countries or the external movement of camels by importation and exportation between countries could lead to the spread of infections of MERS-Cov among camel populations and adding a risk of zoonotic transmission. The virus has shown limited ability to infect people outside of hospitals, triggering outbreaks in healthcare facilities as experienced in Saudi Arabia in 2014-2016 and the Republic of Korea in 2015. The Republic of Korea had a MERS-CoV outbreak in 2015that resulted in 186 cases, 38 fatalities, and billions of dollars of losses to the economy (Hui et al., 2015; Joo et al., 2019). Fortunately, the global threat of MERS infection is declining in the last few years (Donnelly et al., 2019).

MERS-CoV has been transmitted from person to person in health care facilities in several clusters with evidence of limited transmission among family members in private and public places (Assiri et al., 2013; Müller et al., 2014). The severity of MERS infections among human patients ranges from severe cases to mild or asymptomatic (Zaki, 2012; Assiri et al., 2013).

Camel infection with MERS-CoV has been recorded worldwide particularly in the Middle East countries (Reusken et al., 2013; Alagaili et al., 2014; Falzarano et al., 2017; Saqib et al., 2017; Kasem et al., 2018a, b). Till now, dromedary camels had been thought to be the sole maintenance host and principal reservoir of $\mathrm{MERS}-\mathrm{CoV}$, however, the way of spread of MERS-CoV from camel reservoirs to susceptible human contacts remains unclear (Alagaili et al., 2014; Azhar et al., 2014). MERS-CoV was detected in dromedaries associated with MERS infected patients in KSA, and zoonotic transmission of the virus has been proposed (Kasem et al., 2018b).

Among the main Coronaviruses of concern, animal reservoirs are included in Severe Acute Respiratory Syndrome (SARS), MERS-CoV, and even in newly emerged coronavirus disease 2019 (COVID-19) were reported (Fung et al., 2021; Gautam et al., 2020). Despite the high MERS- CoV's fatality rate (35\%) in severe cases, there are missed knowledge gaps on the virus infections in both veterinary and human aspects (Kelly-Cirino et al., 2019). Therefore, more research is needed to better understand MERS-CoV circulation in camels and to prevent human illnesses from spreading. Regular and extensive epidemiological studies of MERS coronavirus infections in camels and contact persons are needed. In this study, surveillance of camels, being probable source and reservoir of laboratory-confirmed MERS-CoV human patients reported from the Ministry of Health (MOH), Riyadh, Saudi Arabia, was done for MERS-CoV genetic material to assess the potentials of zoonotic transmission of MERS infection.

\section{MATERIALS AND METHODS}

\section{SAMPLES}

The current study was designated as a part of the continuous collaborative epidemiological response to laboratoryconfirmed MERS-CoV human cases who contacted camels or ingested undercooked camel meat unpasteurized camel milk within one week before the onset of the clinical symptoms. The study was extended for three years 20172019 and was conducted at the Ministry of Environment, Water, and Agriculture (MEWA), in cooperation with the Ministry of Health (MOH), Saudi Arabia.

Upon issuing official notifications by the $\mathrm{MOH}$, The Emergency Center at MEWA directed the responsible local veterinary clinic to send qualified veterinarian teams to target camel flocks for clinical investigation and sample collection. During the study period, among a total of 91 reports received from $\mathrm{MOH}$, distributed throughout the Kingdom of Saudi Arabia, fifty-one reports of camel contact patients or patients who ingested raw or undercooked products before developing the characteristic clinical symptoms. The other 40 reports had lived in urban areas and had neither direct nor indirect association with animals. The number of samples collected from camels was related to the number of animals in the flock/flocks in households.

A total of 449 nasal swab samples were collected from dromedaries under strict precautions. The collected samples were transported quickly under chilling conditions to the Central Veterinary Laboratory, MEWA, Riyadh in virus transport media (VTM) (COPAN, Italia, Italy). Following confirmation of the RT-PCR results, all MERS-CoV RNA-positive camels were separately isolated and regularly observed until two successive negative testing results were obtained.

\section{EXAMINATION OF DROMEDARIES FOR MERS-COV RNA BY QRT-PCR}

Dromedaries were examined for MERS coronavirus RNA by qRT-PCR using specific primers for detection of the Upstream E gene (UpE) of MERS-CoV according to the protocol of Corman et al. (2012). The positive samples by targeting the UpE gene were further examined by $\mathrm{qRT}$ PCR assay of ORF1a as described previously (Corman et al., 2012; WHO, 2013).

Total RNA was extracted from the collected swabs 
using a viral RNA extraction kit (Qiagen), following the manufacturer's instructions (Qiagen $\mathrm{GmbH}$, Hilden, Germany). The RT-PCR was performed using a LightMix Molecular Dx MERS-CoV upE kit (Roche), following the recommended protocols of the manufacturer.

\section{RESULTS AND DISCUSSION}

\section{The PERCENTAge OF SUSPECTED ZOONOTIC CASES} AMONG LABORATORY-CONFIRMED CASES OF MERS

\section{INFECTION}

A total of 91 reports were received from $\mathrm{MOH}$ about MERS patients who have had contact with camels. The reports were epidemiologically investigated about residence in rural areas, contact with camels, and their products. The analysis of the questionnaire revealed that out of 91 cases of MERS, 51 (56\%) of which were related to dromedaries and the rest had no relation to animals (Table 1, Figure 1). Based on the directed questionnaire to positive human patients to MERS-CoV throughout the study period, the percentage of patients who contacted camels or acquiring infection by ingestion of raw milk or undercooked meat from camels was $56 \%$. These cases were distributed in 11 regions of the Kingdom of Saudi Arabia. The percentage varied according to region, most cases were distributed in Riyadh (12/28, 42.9\%), East provinces (6/14, 42.9\%), Makkah (5/11, 45.5\%), and Taif (7/11, 63.6\%). The percentage of cases with suspected animal-acquired infections reached 100\% in Bahaa, Gazan, Makkah, Jouf, and Tabuk regions, whereas that percentage was varied in other regions.

Table 1: Number of MERS human cases and the number and percent of patients with history of contacting camels in different regions in Saudi Arabia (2017-2019).

\begin{tabular}{|llll}
$\begin{array}{l}\text { Percent } \\
\text { contacted } \\
\text { camels }\end{array}$ & $\begin{array}{l}\text { No of repos } \\
\text { roceived from } \\
\text { MOH }\end{array}$ & Region \\
\hline $42.9 \%$ & 12 & 28 & Riyadh \\
\hline $55.6 \%$ & 5 & 9 & ALQassim \\
\hline $42.9 \%$ & 6 & 14 & East Provinces \\
\hline $50 \%$ & 1 & 2 & Northern Boundaries \\
\hline $80 \%$ & 4 & 5 & Najran \\
\hline $100 \%$ & 1 & 1 & Bahaa \\
\hline $100 \%$ & 2 & 2 & Gazan \\
\hline $45.5 \%$ & 5 & 11 & Makkah \\
\hline $100 \%$ & 2 & 2 & Al-Madinah \\
\hline $100 \%$ & 3 & 3 & Asir \\
\hline $63.6 \%$ & 7 & 11 & Taif \\
\hline $100 \%$ & 2 & 2 & Tabuk \\
\hline $100 \%$ & 1 & 1 & Jouf \\
\hline $56 \%$ & 51 & 91 & Total \\
\hline
\end{tabular}

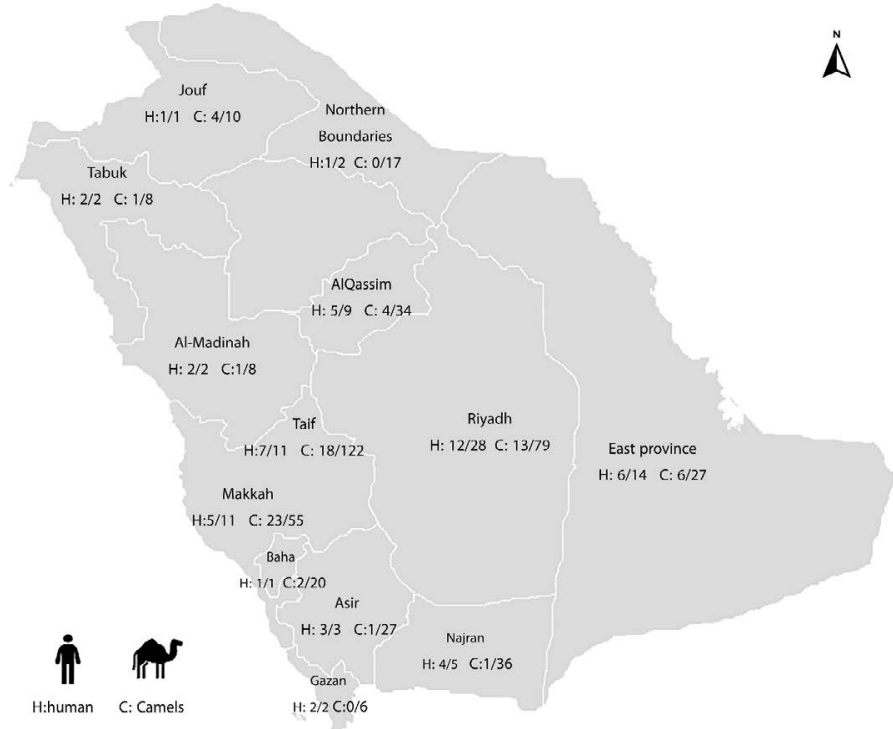

Figure 1: Distribution of MERS human confirmed cases with a history of contact with animals in different regions of Saudi Arabia (H: human), and distribution of camels infected with MERS RNA related to confirmed human cases (C: Camels).

\section{Prevalence of MERS CoV genome among the COLLECTED CAMEL SAMPLES}

Of the 449 nasal samples collected from dromedaries that had a relation with MERS subjects from all the regions of KSA, 74 (16.5\%) were positive for MERS coronavirus; indicating the presence of active viral infection. Of the 74 positive camels, the higher positivity was recorded in Makkah (23/55; 41.8.\%), Jouf (4/10; 40\%), and East Provinces $(6 / 27 ; 22.2 \%)$ while the moderate positivity was recorded in Riyadh (13/79; 16.5\%), Taif (18/122; 14.8\%), Tabuk and Al-Madinah (1/8; 12.5\%), Al-Qassim (4/34; $11.8 \%)$ and Bahaa $(2 / 20 ; 10 \%)$ and lower positivity to MERS-CoV RNA were detected in Asir (1/27; 3.7\%), Najran ( $1 / 36 ; 2.8 \%)$ and finally Gizan and Northern Boundaries (0\%) (Table 2, Figure 1).

MERS-CoV was firstly detected in humans in September 2012 in KSA (Zaki et al., 2012). Following that, the MERS infection was widespread and was documented in 27 countries. The KSA is currently recognized to have the world's largest MERS infected human cases with a high fatality rate reaching up to $30 \%$ (WHO, 2020). The mortalities caused by MERS are higher compared with the mortality rate among patients with similar infections such as s SARS infection (9.5\%) and COVID-19 (2.3\%) (Petrosillo et al., 2020). Moreover, several earlier studies have found a high prevalence of antibodies to MERS-CoV among camels from different countries (Alagaili et al., 2014; Meyer et al., 2014; Saqib et al., 2017; Kasem et al., 2018b; Alharbi et al., 2020). Dromedary camels have been documented as the sources of MERS-CoV infections. However, the mode of transmission has not fully clarified 
with a probability of infection by direct contact camels or by contact with their body fluids or by ingesting raw or undercooked milk or meat (Mohd et al., 2016). This situation necessitates the ongoing investigation of MERS$\mathrm{CoV}$ in camels associated with MERS-infected cases.

Table 2: The prevalence of MERS-CoV RNA among camels related to MERS patients in different regions in Saudi Arabia 2017-2019.

\begin{tabular}{|llll|}
$\begin{array}{l}\text { Percentage } \\
\text { of positivity }\end{array}$ & $\begin{array}{l}\text { No of positive No of } \\
\text { camels to } \\
\text { MERS RNA }\end{array}$ & $\begin{array}{l}\text { Region } \\
\text { examed } \\
\text { camels }\end{array}$ & \\
\hline $16.5 \%$ & 13 & 79 & Riyadh \\
\hline $11.8 \%$ & 4 & 34 & ALQassim \\
\hline $22.2 \%$ & 6 & 27 & East Provinces \\
\hline $0 \%$ & 0 & 17 & Northern Boundaries \\
\hline $2.8 \%$ & 1 & 36 & Najran \\
\hline $10 \%$ & 2 & 20 & Bahaa \\
\hline $0 \%$ & 0 & 6 & Gazan \\
\hline $41.8 \%$ & 23 & 55 & Makkah \\
\hline $12.5 \%$ & 1 & 8 & Al-Madinah \\
\hline $3.7 \%$ & 1 & 27 & Asir \\
\hline $14.8 \%$ & 18 & 122 & Taif \\
\hline $12.5 \%$ & 1 & 8 & Tabuk \\
\hline $40 \%$ & 4 & 10 & Jouf \\
\hline $16.5 \%$ & 74 & 449 & Total \\
\hline & & & \\
\hline
\end{tabular}

Our results showed that a total of 91 reports were received from $\mathrm{MOH}$ about MERS patients contacted with camels. The reports were epidemiologically investigated about residence in rural areas with contact with camels or ingested their products. The high percentage of human patients of MERS-CoV infections related to dromedaries (56\%) was consistent with previous documents (Azhar et al., 2014; Kasem et al., 2018a). According to this study, $16.5 \%$ of camels who were in contact with positive persons showed positivity to MERS-CoV RNA. These positive camels were distributed in diverse parts of Saudi Arabia, ranging from $41.8 \%$ in Makkah to $2.8 \%$ in Najran. This data was consistent with fact that the direct contact with dromedary camels is one of the modes of spread of the MERS-CoV to humans and confirming that dromedary camels were the major reservoirs of infection (Memish et al., 2013; Azhar et al., 2014; Farag et al., 2015; Muhairi et al., 2016; Kasem et al., 2018a). Furthermore, our investigation of nasal swabs collected from camels revealed that the maximal virus shedding period from infected camels was two weeks following the first detection without clinical signs on infected camels, which was consistent with earlier research (Memish et al., 2013; Muhairi et al., 2016; Kasem et al., 2018a). These findings highlighted the urgent need for additional research into the pathways by which MERS$\mathrm{CoV}$ is spillover from camels to human beings. The high seroprevalence of MERS-CoV in camels warrants the establishment of risk-based surveillance programs of the disease among camels and humans particularly among people who are at higher risk of infection by contacting camels or immunocompromised patients or persons in health care facilities.

In conclusion, the detection of the MERS-CoV genome among camel samples associated with confirmed MERS subjects suggested that the virus is prevalent in Saudi Arabia. This data support the theory of zoonotic infections of MERS-CoV by direct contact with the infected camels. However, to fully comprehend the mode of transmission of MERS-CoV infection and the zoonotic pathway, a comprehensive longitudinal investigation is required.

\section{NOVELTY STATEMENT}

This data supported the theory of zoonotic infections of MERS-CoV from camels.

\section{AUTHOR'S CONTRIBUTION}

All authors contributed equally. All authors interpreted the data, discussed the results, and approved the final manuscript revised the manuscript.

\section{CONFLict OF INTEREST}

The authors have declared no conflicts of interest.

\section{ETHICAL APPROVAL}

MEWA ethical committee approved the study.

\section{REFERENCES}

-Alagaili AN, Briese T, Mishra N, Kapoor V, Sameroff SC, Burbelo PD, de Wit E, Munster VJ, Hensley LE, Zalmout IS, Kapoor A, Epstein JH, Karesh WB, Daszak P, Mohammed OB, Lipkin WI (2014). Middle East respiratory syndrome coronavirus infection in dromedary camels in Saudi Arabia. mBio. 5(2):e00884-14.

-Alharbi NK, Ibrahim OH, Alhafufi A, Kasem S, Aldowerij A, Albrahim R, Abu-Obaidah A, Alkarar A, Bayoumi FA, Almansour AM, Aldubaib M, Al-Abdely HM, Balkhy HH, Qasim I (2020). Challenge infection model for MERS-CoV based on naturally infected camels. Virol. J., 17(1): 77.

-Assiri A, Al-Tawfiq JA, Al-Rabeeah AA, Al-Rabiah FA, AlHajjar S, Al-Barrak A, Flemban H, Al-Nassir WN, Balkhy $\mathrm{HH}$, Al-Hakeem RF, Makhdoom HQ, Zumla AI, Memish ZA (2013). Epidemiological, demographic, and clinical characteristics of 47 cases of Middle East respiratory syndrome coronavirus disease from Saudi Arabia: A descriptive study. Lancet Infect. Dis., 13(9): 752-761.

- Azhar EI, El-Kafrawy SA, Farraj SA, Hassan AM, Al-Saeed MS, Hashem AM, Madani TA (2014). Evidence for camelto-human transmission of MERS coronavirus. N. Engl. J. Med. 370(26): 2499-505. 
- Cauchemez S, Van Kerkhove MD, Riley S, Donnelly CA, Fraser C, Ferguson NM (2013). Transmission scenarios for Middle East Respiratory Syndrome Coronavirus (MERS-CoV) and how to tell them apart. Eur. Surveill, 18(24).

- Conzade R, Grant R, Malik MR, Elkholy A, Elhakim M, Samhouri D, Ben Embarek PK, Van Kerkhove MD (2018). Reported direct and indirect contact with dromedary camels among laboratory-confirmed MERS-CoV Cases. Viruses, 10(8): 425.

- Corman VM, Eckerle I, Bleicker T, Zaki A, Landt O, Eschbach-Bludau M, van Boheemen S, Gopal R, Ballhause M, Bestebroer TM, Muth D, Müller MA, Drexler JF, Zambon M, Osterhaus AD, Fouchier RM, Drosten C (2012). Detection of a novel human coronavirus by realtime reverse-transcription polymerase chain reaction. Euro. Surveill., 17(39): 20285.

-Donnelly CA, Malik MR, Elkholy A, Cauchemez S, Van Kerkhove MD (2019). Worldwide Reduction in MERS Cases and Deaths since 2016. Emerg. Infect. Dis., 25(9): 1758-1760.

- Falzarano D, Kamissoko B, de Wit E, Maïga O, Cronin J, Samaké K, Traoré A, Milne-Price S, Munster VJ, Sogoba N, Niang M, Safronetz D, Feldmann H (2017). Dromedary camels in northern Mali have high seropositivity to MERSCoV. One Health, 3: 41-43.

- Farag EA, Reusken CB, Haagmans BL, Mohran KA, Stalin Raj V, Pas SD, Voermans J, Smits SL, Godeke GJ, Al-Hajri MM, Alhajri FH, Al-Romaihi HE, Ghobashy H, ElMaghraby MM, El-Sayed AM, Al Thani MH, Al-Marri S, Koopmans MP (2015). High proportion of MERS-CoV shedding dromedaries at slaughterhouse with a potential epidemiological link to human cases, Qatar 2014. Infect. Ecol. Epidemiol., 5: 28305.

-Fung M, Otani I, Pham M, BabikJ (2021). Zoonotic coronavirus epidemics: SARS, MERS, and COVID-19. Ann. Allergy Asthma Immunol., 126(4): 321-337.

- Gautam A, Kaphle K, Shrestha B, Phuyal S (2020). Susceptibility to SARS, MERS, and COVID-19 from animal health perspective. Open Vet. J., 10(2): 164-177.

-Hui DS, Perlman S,Zumla A (2015). Spread of MERS to South Korea and China. Lancet. Respir. Med., 3(7): 509-510.

-Joo H, Maskery BA, Berr AD, Rotz LD, Lee YK, Brown CM (2019). Economic Impact of the 2015 MERS Outbreak on the Republic of Korea's Tourism-Related Industries. Health Secur., 17(2): 100-108.

- Kasem S, Qasim I, Al-Doweriej A, Hashim O, Alkarar A, AbuObeida A, Saleh M, Al-Hofufi A, Al-Ghadier H, Hussien R, Al-Sahaf A, Bayoumi F, Magouz A (2018a). The prevalence of Middle East respiratory Syndrome coronavirus (MERS$\mathrm{CoV}$ ) infection in livestock and temporal relation to locations and seasons. J. Infect. Publ. Health, 11(6): 884-888.

-Kasem S, Qasim I, Al-Hufofi A, Hashim O, Alkarar A, AbuObeida A, Gaafer A, Elfadil A, Zaki A, Al-Romaihi A, Babekr N, El-Harby N, Hussien R, Al-Sahaf A, A1Doweriej A, Bayoumi F, Poon LLM, Chu DKW, Peiris M, Perera RAPM (2018b). Cross-sectional study of MERSCoV-specific RNA and antibodies in animals that have had contact with MERS patients in Saudi Arabia. J. Infect. Publ. Health, 11(3): 331-338.

-Kelly-Cirino C, Mazzola, LT, Chua, A, Oxenford, CJ, Van
Kerkhove, MD (2019). An updated roadmap for MERS$\mathrm{CoV}$ research and product development: focus on diagnostics. BMJ Glob. Health, 4(Suppl 2): e001105.

-Memish ZA, Zumla AI, Al-Hakeem RF, Al-Rabeeah AA, Stephens G M (2013). Family cluster of Middle East respiratory syndrome coronavirus infections. N. Engl. J. Med., 368(26): 2487-2494.

- Meyer B, Müller MA, Corman VM, Reusken CB, Ritz D, Godeke GJ, Lattwein E, Kallies S, Siemens A, van Beek J, Drexler JF, Muth D, Bosch BJ, Wernery U, Koopmans MP, Wernery R, Drosten C (2014). Antibodies against MERS coronavirus in dromedary camels, United Arab Emirates, 2003 and 2013. Emerg. Infect. Dis., 20(4): 552-559.

-Mohd HA, Al-Tawfiq JA, Memish ZA (2016). Middle East Respiratory Syndrome Coronavirus (MERS-CoV) origin and animal reservoir. Virol. J., 13: 87.

-Muhairi SA, Hosani FA, Eltahir YM, Mulla MA, Yusof MF, Serhan WS, Hashem FM, Elsayed EA, Marzoug BA, Abdelazim AS (2016). Epidemiological investigation of Middle East respiratory syndrome coronavirus in dromedary camel farms linked with human infection in Abu Dhabi Emirate, United Arab Emirates. Virus Genes, 52(6): 848854.

- Müller MA, Corman VM, Jores J, Meyer B, Younan M, Liljander A, Bosch BJ, Lattwein E, Hilali M, Musa BE, Bornstein S, Drosten C (2014). MERS coronavirus neutralizing antibodies in camels, Eastern Africa, 1983-1997. Emerg. Infect. Dis. 20(12): 2093-2095. https://doi.org/10.3201/ eid2012.141026

- Petrosillo N, Viceconte G, Ergonul O, Ippolito G, Petersen E (2020). COVID-19, SARS and MERS are they closely related?. Clin. Microbiol. Infect., 26(6): 729-734. https:// doi.org/10.1016/j.cmi.2020.03.026

-Reusken CB, Ababneh M, Raj VS, Meyer B, Eljarah A, Abutarbush S, Godeke GJ, Bestebroer TM, Zutt I, Muller MA, Bosch BJ, Rottier PJ, Osterhaus AD, Drosten C, Haagmans BL, Koopmans MP (2013). Middle East Respiratory Syndrome coronavirus (MERS-CoV) serology in major livestock species in an affected region in Jordan, June to September 2013. Eur. Surveill., 18(50): 20662.

-Saqib M, Sieberg A, Hussain MH, Mansoor MK, Zohaib A, Lattwein E, Müller MA, Drosten C, Corman VM (2017). Serologic Evidence for MERS-CoV Infection in Dromedary Camels, Punjab, Pakistan, 2012-2015. Emerg. Infect. Dis., 23(3): 550-551.

-WHO (2013). Laboratory testing for middle east respiratory syndrome coronavirus. Retrieved from: www.who.int/csr/ disease/coronavirus_infections/MERS_Lab_recos_16_ Sept_2013.pdf?ua=1

-WHO (2019). Mers situation update November 2019. Retrieved from https://applications.emro.who.int/docs/EMRPUBCSR-241-2019

-WHO (2020). Middle East respiratory syndrome coronavirus (MERS-CoV) - The Kingdom of Saudi Arabia. Retrieved from https://www.who.int/csr/don/24-february-2020mers-saudi-arabia/en/

-Zaki, AM., van Boheemen, S, Bestebroer, TM, Osterhaus, AD, Fouchier, RA (2012). Isolation of a novel coronavirus from a man with pneumonia in Saudi Arabia. N. Engl. J. Med., 367(19): 1814-1820. 